\title{
Subculturas e valores pessoais: uma investigação na Rio Harley-Davidson
}

\author{
Subcultures and personal values: \\ an investigation at rio harley-davidson
}

\author{
EDUARDO SANTOS ROCHA ZAFANELI* \\ IRENE RAGUENET TROCCOLI** \\ PATRICIA LEITE DA SILVA SCATULINO***
}

\section{RESUMO}

Em virtude dos valores, o consumo, muitas vezes, está mais diretamente relacionado à representatividade e à simbologia de marcas, de bens e de serviços, do que ao valor de uso propriamente dito. Com isso, os valores afetam as decisões de consumo, que acontecem muito mais em função do contexto social e da ligação desse indivíduo com os grupos em que está inserido, do que meramente em função de uma decisão isolada e individual. Por sua vez, as comunidades de marca estimulam o consumo de produtos relacionados à marca, bem como, geram, no consumidor, a reprodução de comportamentos originados e aprendidos no grupo. Este artigo traz o resultado de pesquisa qualitativa baseada na Teoria Meios-Fim, que, utilizando a técnica de soft laddering, examinou quais valores pessoais do consumidor da Rio Harley-Davidson motivam sua participação na comunidade da marca Rio H.O.G. As evidências obtidas junto a homens de 36 a 60 anos de idade revelaram elevada homogeneidade nas respostas, com o surgimento de três valores terminais - pertencimento, segurança e relações calorosas com terceiros. A relevância desta investigação reside na lacuna teórica remanescente na área do comportamento do consumidor desde que foram salientadas as

* Universidade Estácio de Sá. eduardozafaneli@gmail.com .

** Universidade Estácio de Sá. Professora Mestrado em Administração e Desenvolvimento Empresarial. irene.troccoli@estacio.br .

*** Universidade Estácio de Sá. patricialeiteadm@hotmail.com , 
limitações de se estudar a preferência por marcas, enfocando-se o estilo de vida e os valores pessoais. A contribuição teórica advém da surpresa contraintuitiva à incipiente menção à felicidade como sentimento que permeia as relações do grupo.

Palavras-chave: Subculturas. Comunidades de Marca. Valores Pessoais.

\section{Abstract}

Because of values, consumption is often more directly related to the representation and symbolism of brands, goods and services, rather than the use value itself. Thus, values affect consumer decisions, which depend more on the social context and on the connection of that individual with the groups to which he belongs, than merely on an isolated and individual decision. In turn, brand communities stimulate consumer products related to the brand, and lead the consumer to reproduce and the behaviours originated and learned within the groups. This article presents the results of qualitative research based on Means-End Theory and soft laddering technique, that examined which personal values motivate Rio Harley-Davidson members to participate in Rio HOG brand community. Evidence obtained from 36-60 year-old men showed high homogeneity, where three terminal values dominate - belonging, security and warm relationships with others. The relevance of this research lies in the remaining theoretical gap in consumer behavior since the highlighting of the limitations of studying the preference for brands focusing on is the lifestyle and personal values. Theoretical contribution may be found in the counterintuitive surprising low presence of happiness as a feeling amongst the relationships in the group. Key-words: Subcultures. Brand communities. Personal values.

\section{INTRODUÇÃo}

Em virtude dos valores, o consumo, muitas vezes, está mais diretamente relacionado à representatividade e à simbologia de marcas, de bens e de serviços, do que ao valor de uso propriamente dito (FLINT; WOODRUFF, GARDIAL, 1997; BAUMAN, 2001; RUST; ZEITHAML; LEMON, 2001). Com isso, os valores afetam as decisões de consumo, que acontecem muito mais em função do 
contexto social e da ligação desse indivíduo com os grupos em que está inserido, do que meramente em função de uma decisão isolada e individual (HALL, 2006).

Principalmente quando está em questão a aceitação ou a reprovação desse consumidor pelos demais membros de um grupo, suas decisões, sejam elas de consumo ou cotidianas, são fortemente influenciadas pelos chamados grupos de referência (HYMAN, 1942; SHIBUTANI, 1955), devido aos seres humanos serem considerados essencialmente seres sociais (MOURALI; LAROCHE; PONS, 2005). Tal característica, por sua vez, lhes gera desejo de pertencimento a um grupo que, por meio dos laços sociais, o liga a outros indivíduos e o faz sentir-se parte desse grupo (BEARDEN; ETZEL, 1982; RECUERO, 2007).

Percebe-se que, em muitos casos, tal senso de pertencimento gira em torno de grupos de consumidores também conhecidos como comunidades de marca, que compartilham um conjunto de relações sociais com base no uso ou no interesse por um produto ou marca específicos (SOLOMON, 2010; SCHOUTEN; McALEXANDER; KOENIG, 2007; FÜLLER; MATZLER; HOPPE, 2008; SCHAU; MUNIZ; ARNOLD, 2009).

Em virtude dessa forte ligação emocional entre os seus membros, as comunidades de marca tendem a estimular o consumo cada vez maior de produtos relacionados à marca, bem como, a gerar, no consumidor, a reprodução de comportamentos originados e aprendidos no grupo. Por essa razão, para uma análise mais aprofundada a respeito da influência das comunidades de marca sobre o consumidor, faz-se necessária também a investigação da relação desse consumidor com a marca, com a empresa e até mesmo com o produto oferecido (HABIBI; LAROCHE; RICHARD, 2014).

Uma comunidade de marca destacada no mundo das motocicletas é a Harley Owner Group (H.O.G.), criada pela fabricante norte-americana de motocicletas Harley-Davidson, com os objetivos de desenvolver relacionamentos com os clientes proprietários de suas motocicletas, de estimular as práticas comerciais entre esses e de propagar o conceito da marca de liberdade pessoal e a expressão de um estilo de vida destemido e aventureiro (ALVARO, 2014; SCHOUTEN; McALEXANDER, 1995; BAGOZZI; DOLAKIA, 2006). 
Motivada pela lacuna teórica remanescente na área do comportamento do consumidor desde que Holt (1997) salientou as limitações de se estudar a preferência por marcas, enfocando-se o estilo de vida e os valores pessoais, e pela parcimônia que (ainda) se produzem artigos no Brasil sobre a Harley-Davidson e sobre a H.O.G., emergiu a questão da presente pesquisa: quais valores pessoais do consumidor da Rio Harley-Davidson motivam a sua participação na comunidade da marca Rio H.O.G.?

Após a presente introdução, seguem-se mais cinco seções: referencial teórico, aspectos do método, resultados da pesquisa primária, conclusão, e contribuição teórica com sugestões de futuros estudos.

\section{REFERENCIAL TEÓRICO}

\subsection{Valores do Consumidor}

Estudo seminal de Rokeach (1968) aponta os valores como as crenças que conduzem os julgamentos e as ações de um indivíduo, por intermédio de situações e de objetivos específicos, tornando-se critérios de escolhas. Não tendo partido de uma abordagem teórica, mas de um conjunto de suposições plausíveis, mais ou menos independentes, esse autor estudou a natureza dos valores humanos por meio da integração do pensamento filosófico com os conhecimentos da psicologia e com as teorias sociais.

Com isso, ele determinou que os valores remetem à sociedade e se dividem em instrumentais (ambicioso, mente aberta, capaz, alegre, limpo, corajoso, generoso, útil, honesto, imaginativo, independente, intelectual, lógico, amoroso, obediente, gentil, responsável e controlado) e em terminais (vida confortável, vida emocionante, senso de realização, mundo de paz, mundo de beleza, igualdade, segurança familiar, liberdade, felicidade, harmonia interior, amor maduro, segurança nacional, prazer, salvação, autoestima, reconhecimento social, amizade verdadeira e sabedoria), com os primeiros levando aos segundos (ROKEACH, 1968, 1973).

Uma forma alternativa de ver esses valores é a List of Values (LOV), formada por nove elementos essencialmente orientados ao nível individual e que se relacionam com as circunstâncias da vida cotidiana: autorrespeito, segurança, relações calorosas com 
terceiros, autorrealização, sentimento de dever cumprido, ser bem respeitado, pertencimento, diversão, e animação. Baseou-se na Teoria da Adaptação Social de Kahle (1983), resultando de simplificação dos instrumentos desenvolvidos por Maslow (1954), por Feather (1975) e, especialmente, por Rokeach (1973) para medir a importância dos valores.

Em seguida a esses esforços, surgiram questionamentos quanto ao estudo dos valores pessoais dever envolver a compreensão dos efeitos e do significado das preferências axiológicas de cada pessoa, o que levou a lista de Rokeach (1973) ser vista como uma lista de valores sem aparente relação entre si (ROHAN, 2000).

Isso levou à construção de Schwartz (1992, 2005), para quem valores são crenças e metas conscientes que guiam a seleção e a avaliação de ações, de objetivos, de pessoas e de situações, e que podem ser interpretados como construtos motivacionais que transcendem situações e ações específicas. Totalizando uma dezena de tipos motivacionais, e apoiados em objetivos gerais que atuam como princípios orientadores na vida dos indivíduos representados como metas desejáveis, transituacionais e de importância variável, seriam respostas às necessidades dos humanos como seres biológicos de bem-estar e de sobrevivência de grupos, como também advindas de interação social: poder, realização, hedonismo, estimulação, autodeterminação, universalismo, benevolência, tradição, conformidade e segurança.

No Brasil, a utilização dessas teorias ainda é incipiente em relação ao seu potencial de contribuição às decisões gerenciais, o que pode justificar-se porque ainda lhes restam lacunas a serem respondidas (PIMENTA; PIATO; VILAS-BOAS, 2014). Essas lacunas se aguçam quando se deseja cruzar esse construto com outros que são caros à pesquisa de comportamento do consumidor. Por exemplo, no caso de clientes de serviços bancários, além de não haver efeito moderador dos segmentos de valores pessoais na relação entre atitudes e fases da lealdade, haveria diferenças nas fases cognitiva, afetiva e de ação entre os segmentos baseados nos valores pessoais (HENRIQUE; MONTEIRO; MATOS, 2013). 


\subsection{Cultura como fator de influência no comportamento do consumidor}

Cultura é um complexo que combina crenças, moral, conhecimentos, artes, leis, hábitos e costumes adquiridos pelo indivíduo, como fruto da sua relação com os demais membros da sociedade em que está inserido (BAUDRILLARD, 1995; LARAIA, 2006). Mais importante, é por meio do consumo - moldado em todos os seus sentidos por considerações culturais (HOFSTEDE, 2001; LARAIA, 2006) - que a cultura expressa princípios, estilos de vida, ideais, categorias, identidades sociais e projetos coletivos. Isso porque o consumo pode ser entendido como uma expressão das emoções e de desejos do indivíduo, veículo revelador de suas crenças, de suas atitudes e de seus valores pessoais (ROCHA; PEREIRA, 2009).

A cultura adquiriu, ainda, uma dimensão processual por intermédio da qual os indivíduos buscam significados e sentido nas formas materiais, sociais e institucionais existentes, para a construção das suas identidades como seres humanos (McCRACKEN, 2003; CAMPBELL, BARBOSA, 2006). Por essa razão, as relações estabelecidas entre cultura e consumo têm assumido forte papel de estruturação de relações sociais e de valores, que compartilham aspectos culturais de diferentes grupos (DOUGLAS; ISHERWOOD, 2006).

Essa associação pode ser mais bem compreendida sob a ótica da chamada Teoria da Cultura do Consumo, que aponta a relação existente entre os significados culturais, o mercado e as ações de consumo como um elemento fundamental para a construção de tal cultura (ARNOULD; THOMPSON, 2005). Por meio de tal teoria, utilizando a cultura e o consumo como base de fundamentação de investigação é possível analisar as manifestações culturais existentes nas diversas formações sociais, identificar a distribuição heterogênea dos significados e entender a multiplicidade de grupos.

Tal compartilhamento cultural se manifesta muitas vezes por meio das chamadas subculturas de consumo, "um subgrupo distinto da sociedade cujos membros selecionam a si mesmos como base no compromisso compartilhado em relação a uma classe de produto, marca ou atividade de consumo específica" (SCHOUTEN; McALEXANDER, 1995, p. 43). 
Assim, cultura e consumo possuem relação historicamente sem precedentes, que também tem possibilitado a consideração de que o consumo, na sociedade contemporânea, produz sentidos e identidades, independentemente da aquisição de um produto (McCRACKEN, 2003; CAMPBELL; BARBOSA, 2006). Em outras palavras, a cultura do consumo vai além da simples compra de produtos e de serviços para a satisfação das necessidades, tendo passado a englobar principalmente o consumo de valores e de imagens por parte do consumidor (BAUDRILLARD, 1995; GONÇALVES, 2009; ALFINITO; TORRES, 2012).

\subsection{Socialização do ConSUMidor - Agrupamentos}

Tendo em vista que um grupo social existe quando duas ou mais pessoas, possuindo relacionamentos interpessoais onde seus comportamentos sejam interdependentes, compartilham um conjunto de crenças, de valores ou de normas (HAWKINS; MOTHERSBAUGH; BEST, 2007), tem-se que a interação social é considerada fator vital para a existência e sobrevivência de um grupo social.

Os grupos sociais se diferenciam por apresentar diferentes formatos, como frequência e tipos de contato, natureza da associação, e grau de formalidade. Ao mesmo tempo, o contexto social de um grupo é essencialmente responsável pela construção de um ambiente confiável de interação (GIRALDI; IKEDA, 2010). Tal confiança gera valores pessoais explícitos e implícitos, e tem impacto positivo sobre a estabilidade de uma relação grupal conforme aumenta a interação cooperativa entre os seus membros (ARGO; DAHL; MANCHANDA, 2005).

A afiliação do indivíduo ao grupo permite não somente a construção dessa identidade social como também da autovalorização. Percebe-se que a interação com os demais membros do grupo interfere na autopercepção - ou seja, quando ocorre uma forte ligação e identificação do indivíduo com o seu grupo, ele se sente mais valorizado como pessoa (HACKEL; LOOSER; VAN BAVEL, 2014). Portanto, a identidade social se manifesta por meio do sentimento de pertencimento a um grupo, sendo resultante do compartilhamento de emoções, de estereótipos e de imagens, que conectam o indivíduo aos elementos mais superficiais da cultura (AÑÑN; NIQUE, 2008). 


\subsection{Grupos de Referência}

Grupo de referência é um grupo ou uma pessoa que influencia significativamente o comportamento, as aspirações e as avaliações dos indivíduos (HYMAN, 1942; BEARDEN; ETZEL, 1982; BLACKWELL; MINIARD; ENGEL, 2011), os quais buscam aceitação e aprovação para construir e para estruturar os seus valores pessoais (MOURALI; LAROCHE; PONS, 2005). Esses grupos, que podem ser primários, secundários, formais, informais, aspiracionais e dissociativos (SOLOMON, 2010), influenciam fortemente as decisões dos indivíduos, sejam elas de consumo ou cotidianas, principalmente quando se está em questão a aceitação ou a reprovação desse indivíduo pelo grupo. Isso porque os comportamentos, os valores e as atitudes dos membros de um grupo tornam-se padrões de julgamento e de conduta do indivíduo (BROCATO; VOORHEES; BAKER, 2012).

A influência dos grupos de referência sobre o indivíduo pode ocorrer de três maneiras (KELMAN, 1961): 1) por meio da internalização, quando o indivíduo aceita a interferência do grupo por estar de acordo com os seus valores; 2) pela identificação, quando o indivíduo adota um comportamento por estar associado a um grupo; e 3) por intermédio da conformidade, quando o indivíduo aceita a influência dos demais membros do grupo objetivando a aceitação e a aprovação do grupo, evitando, assim, a exclusão, por exemplo.

Um elemento muito presente nos estudos sobre grupos de referência é o desejo de pertencimento de um indivíduo a um grupo, entendido como o sentimento que, por meio dos laços sociais, liga os indivíduos e os faz sentir-se parte de um grupo (RECUERO, 2007). Trata-se de quando o sujeito adquire uma "consciência de espécie", de que agora faz parte de um "bando" com características semelhantes as dele (HICKMAN; WARD, 2007).

Quando um grupo de referência é formado em função de uma marca ou produto, surge uma comunidade de marca (DHOLAKIA; BLAZEVIC; WIERTZ, 2009).

\subsection{Comunidades de Marca}

Uma comunidade de marca é um grupo de consumidores que compartilham um conjunto de relações sociais com base no uso ou no interesse por um produto (MAFFESOLI, 1996; MUÑIZ; SHAU, 
2005). Utilizadas como ferramentas estratégicas de relacionamento e de fidelização entre os consumidores e a marca, tais comunidades são vistas também como canais de autoexpressão, como locais de suporte social e como centros condutores de informação (ALGESHEIMER; DHOLAKIA, 2008). Além disso, exercem forte influência sobre os seus membros e estabelecem relacionamentos de longo prazo com os consumidores (CARLSON; SUTER; BROWN, 2008).

As comunidades de marca facilitam os relacionamentos da empresa com os seus consumidores já que, por meio delas, os consumidores se encontram mais propensos e solícitos ao envolvimento emocional do que, por exemplo, em estratégias de marketing de relacionamento com o cliente. Também propiciam o aumento do conhecimento das empresas a respeito do comportamento do consumidor, proporcionado pela interação social (HABIBI; LAROCHE; RICHARD, 2014).

São várias as vantagens do sentimento de pertencimento do indivíduo em relação à comunidade de marca de que faz parte: quanto maior ele for, maior a propensão de promover a marca por intermédio da comunicação boca a boca, maior o interesse em participar de eventos relacionados à marca, maior a lealdade à marca frente aos concorrentes, e tanto maior o interesse pela história da marca. Por sua vez, isso implica o fortalecimento de um comportamento emocional com a comunidade em que o indivíduo está inserido (CARLSON; SUTER; BROWN, 2008).

\section{Método}

Ancorada na Teoria Meios-Fim (REYNOLDS; OLSON, 2010), a pesquisa é de abordagem qualitativa-quantitativa, descritiva e exploratória quanto aos fins; quanto aos meios é bibliográfica e de campo (GIL, 2011; VERGARA, 2010).

O levantamento e o tratamento das informações primárias ocorreram por meio do laddering, acontecendo entre março e novembro de 2014. Visando ao aumento da qualidade dos resultados via triangulação de métodos (FLICK, 2009), paralelamente foi realizada observação não participante com inspiração etnográfica.

Houve 12 visitas à concessionária Rio Harley-Davidson (Rio H.O.G.) no bairro carioca do Recreio dos Bandeirantes, dedicadas 
apenas à observação não participante, e sete visitas dedicadas à realização das 14 entrevistas e para novas experiências etnográficas.

Para as 14 entrevistas, foram selecionados aleatoriamente donos de motocicletas Harley-Davidson (Harleyros) do sexo masculino, sem distinção de tempo de pertencimento ao grupo ou de modelo de motocicleta, enquadrados na faixa etária entre 35 a 60 anos, membros da H.O.G. da Rio H.O.G. - ou seja, heavy users do produto HarleyDavidson - frequentadores dos cafés da manhã semanais do grupo que ali ocorrem com objetivos variados. Um dos entrevistados era o presidente da Rio H.O.G., outro era membro da diretoria dessa comunidade, e os demais eram membros sem cargos na estrutura da Rio H.O.G. (ver Tabela 1).

Tabela 1 - Perfil dos entrevistados: idade, profissão e tempo de pertencimento a Rio H.O.G.

\begin{tabular}{|c|c|c|c|}
\hline $\begin{array}{l}\text { Número do } \\
\text { entrevistado }\end{array}$ & $\begin{array}{l}\text { Idade } \\
\text { (em anos) }\end{array}$ & Profissão & $\begin{array}{l}\text { Tempo de pertencimento a } \\
\text { Rio H.O.G. }\end{array}$ \\
\hline 01 & 41 & Advogado & 05 anos \\
\hline 02 & 36 & Publicitário & 02 anos \\
\hline 03 & 53 & Engenheiro & 08 anos \\
\hline 04 & 55 & Empresário & 14 anos \\
\hline 05 & 49 & Advogado & 07 anos \\
\hline 06 & 60 & Arquiteto & 10 anos \\
\hline 07 & 39 & Médico & 02 anos \\
\hline 08 & 54 & Empresário & 06 anos \\
\hline 09 & 59 & Professor & 07 anos \\
\hline 10 & 52 & Empresário & 12 anos \\
\hline 11 & 35 & Publicitário & 05 anos \\
\hline 12 & 46 & Engenheiro & 02 anos \\
\hline 13 & 60 & Médico & 25 anos \\
\hline 14 & 48 & Empresário & 03 anos \\
\hline
\end{tabular}

Fonte: Elaboração do autor

Foi utilizada a técnica de soft laddering (REYNOLDS; GUTMAN, 1988; DIBLEY; BAKER, 2001; CARDOSO SOBRINHO et al. 2010). A 
entrevista com o membro da presidência do grupo ocorreu em um restaurante e as demais ocorreram dentro da unidade Rio Harley-Davidson.

O conteúdo das entrevistas foi tratado seguindo as orientações colocadas por Ikeda, Campomar e Chamie (2014), sendo que:

1) a análise foi feita de modo manual, sem o auxílio de softwares;

2) como se trata da análise de um serviço e não de um produto, os atributos que poderiam ser apontados pelos entrevistados seriam sempre abstratos;

3) para a qualificação dos valores, como referência inicial foram utilizados os nove valores da LOV, e à medida que era executada a análise de conteúdo do material das entrevistas, atentou-se para a eventual localização de outros valores que ali tivessem surgido de forma espontânea (contudo, isso não ocorreu). A opção pela LOV em detrimento dos valores propostos por Schwartz (1992, 2005), e que têm tido amplo uso na pesquisa recente em Administração, se deveu a ela ser centrada no indivíduo e se relacionar com as necessidades pessoais, sendo adequada a estudos de comportamento de consumo (VALLETTE-FLORENCE, 1998);

4) as consequências e os valores não foram desdobrados em dois níveis cada, opção apoiada em quatro justificativas, sancionadas por especialistas na técnica de laddering (VELUDO-DE-OLIVEIRA, 2015; LEÃO, 2014): a) a orientação de Olson e Reynolds (2010) de que esse desdobramento não traz diferencial relevante para a maior parte das aplicações de negócios ou até mesmo para a maior parte dos propósitos teóricos; b) em se tratando de um serviço, não seria o caso de se terem consequências funcionais; e c) os nove valores da LOV não são formalmente separados em instrumentais e terminais; e

5) a qualificação dos elementos em atributos, consequências e valores foi realizada unicamente pelo autor da pesquisa, providência reforçada pela dose extra de subjetividade implicada pela abstração típica dos serviços, e que converge com o que pregam Reynolds e Olson (2010, p. 78): “É óbvio que a codificação é processo complicado que dá muita latitude ao pesquisador (...). O entrevistador, que conduziu a conversa a ser codificada, é o melhor codificador possível, porque ele lembrará parte da informação contextual". 


\section{Resultados dA PESQUisa}

Com o material levantado nas entrevistas para a fase de laddering, foram identificados um atributo, 12 consequências e seis valores (ver Quadro 1), e foram constituídos 74 ladders individuais, que serviram ao desenvolvimento da Matriz Quadrada de Implicação.

Seguindo-se os procedimentos sugeridos por Reynolds e Gutman (1988), elaborou-se o MHV (ver Figura 1), por meio do qual verificou-se a formação de 10 cadeias (ver Tabela 2). Entre aquelas com percepção dominante - traduzida na frequência 12 - destacaram-se as três primeiras cadeias, cujos código, nomes, elementos formadores (atributo, consequências e valores) e frequências encontram-se na Tabela 3.

Figura 1 - Mapa Hierárquico de Valor (MHV)

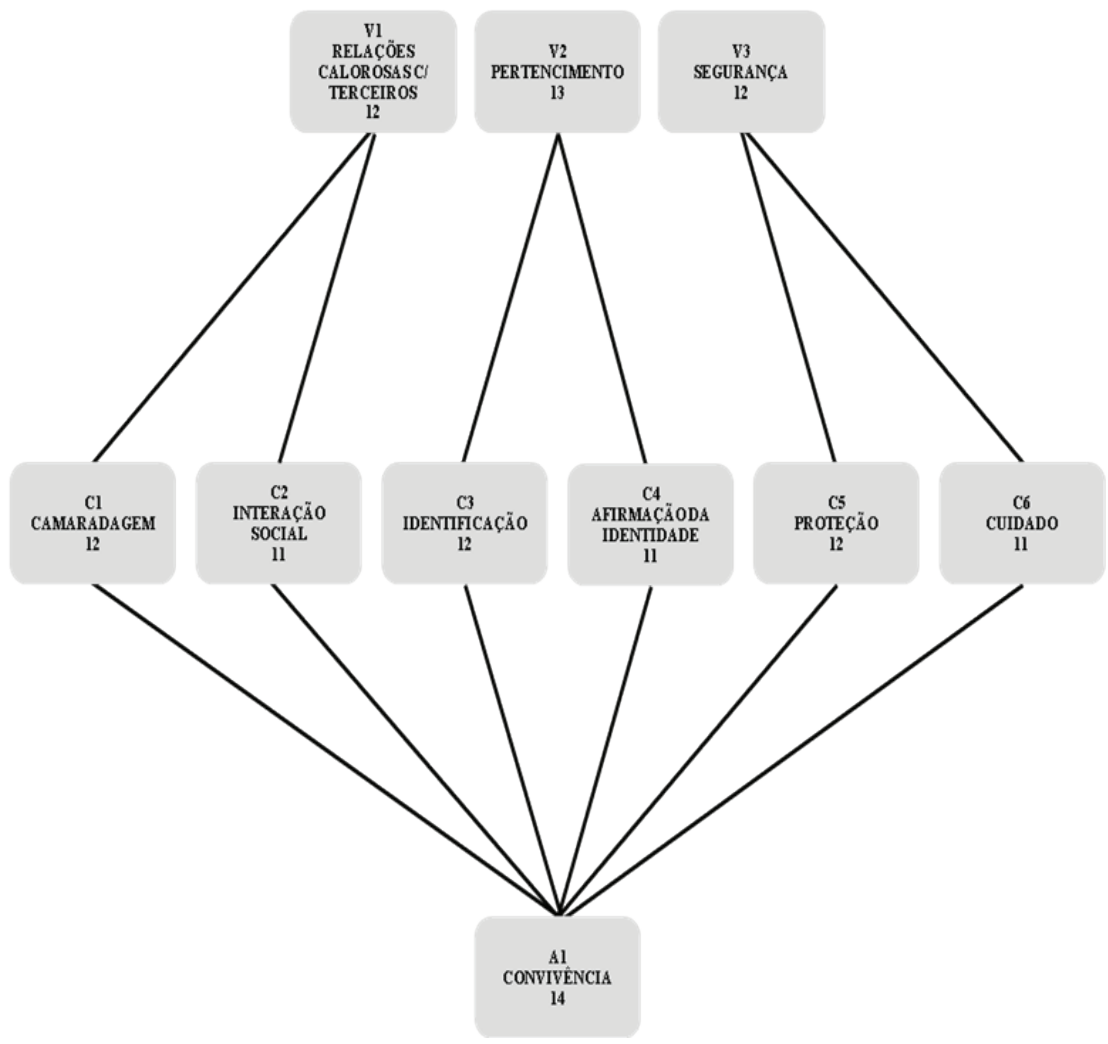

Fonte: Elaboração do autor 
Quadro 1 - Atributos, consequências e valores identificados nas entrevistas - Respectivos código, nomes e descrição

\begin{tabular}{|c|c|c|}
\hline TIPO & CÓDIGO & NOMES E DESCRIÇÃO \\
\hline Atributo & A1 & $\begin{array}{l}\text { Convivência - Experiência de encontrar e estar com os amigos, de } \\
\text { conversar, de estar com o grupo. }\end{array}$ \\
\hline \multirow{12}{*}{ 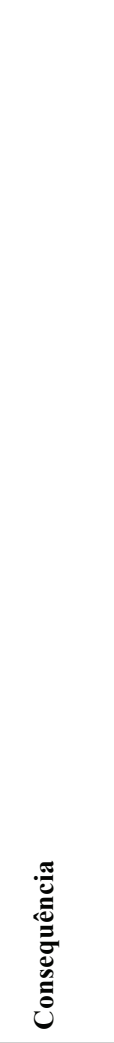 } & $\mathrm{C} 1$ & $\begin{array}{l}\text { Camaradagem - Oportunidade de usufruir de amizade, de compa- } \\
\text { nheirismo, de cumplicidade, de conexão, de união, de compartilha- } \\
\text { mento da vida. }\end{array}$ \\
\hline & $\mathrm{C} 2$ & $\begin{array}{l}\text { Interação Social - Ter pessoas por perto, de fazer amigos, de se sentir } \\
\text { amado, de não se sentir sozinho ou abandonado, de fortalecer os laços } \\
\text { afetivos, de ter relacionamento presencial com outros. }\end{array}$ \\
\hline & $\mathrm{C} 3$ & $\begin{array}{l}\text { Identificação - interesse por grupos ou pessoas que possuem conside- } \\
\text { rável afinidade e estilo de vida semelhante. }\end{array}$ \\
\hline & $\mathrm{C} 4$ & $\begin{array}{l}\text { Afirmação da Identidade - Poder expor sua identidade verdadeira aos } \\
\text { demais do grupo sem se preocupar com rótulos ou julgamentos. }\end{array}$ \\
\hline & C5 & Proteção - Sentir-se protegido quando se está com o grupo. \\
\hline & C6 & $\begin{array}{l}\text { Cuidado - Saber que tem amigos que ajudam e que se ajudam num } \\
\text { cuidado mútuo, saber que tem parceiros com quem contar em mo- } \\
\text { mentos difíceis. }\end{array}$ \\
\hline & $\mathrm{C} 7$ & Vigor - Sensação de estar cheio de vida, vivo, animado. \\
\hline & $\mathrm{C} 8$ & $\begin{array}{l}\text { Relaxamento - Descontrair, relaxar, esquecer da vida, desligar do } \\
\text { mundo. }\end{array}$ \\
\hline & C9 & $\begin{array}{l}\text { Afirmação da Masculinidade - Sentimento de que é mais viril, mais } \\
\text { homem, mais macho, pelo fato de estar interagindo com outros indiví- } \\
\text { duos do gênero masculino. }\end{array}$ \\
\hline & $\mathrm{C} 10$ & $\begin{array}{l}\text { Valorização - Sentimento de reconhecimento social através do enalte- } \\
\text { cimento ou de demonstrações de afeto pelo grupo. }\end{array}$ \\
\hline & $\mathrm{C} 11$ & $\begin{array}{l}\text { Ampliação de Rede de Relacionamento - Busca do aumento da rede } \\
\text { de contatos profissionais (conhecida como networking) por meio da } \\
\text { convivência em grupos. }\end{array}$ \\
\hline & $\mathrm{C} 12$ & $\begin{array}{l}\text { Felicidade - Sentimento experimentado como resultado de alegria e } \\
\text { realizações extremas. }\end{array}$ \\
\hline \multirow[b]{6}{*}{$\frac{0}{\pi}$} & $\mathrm{V} 1$ & $\begin{array}{l}\text { Relações Calorosas com Terceiros - Desejo de ser querido pelos } \\
\text { demais indivíduos. }\end{array}$ \\
\hline & V2 & $\begin{array}{l}\text { Pertencimento - Necessidade de inclusão, de pertencer a um grupo } \\
\text { ou a uma comunidade. }\end{array}$ \\
\hline & V3 & Segurança - Senso de cuidado, de proteção, de abrigo, de amparo. \\
\hline & V4 & $\begin{array}{l}\text { Autorrealização - Alcance de conquistas pessoais nos âmbitos pessoal, } \\
\text { profissional ou financeiro. }\end{array}$ \\
\hline & V5 & $\begin{array}{l}\text { Diversão - Sensação de descontração, de desprendimento da realida- } \\
\text { de. }\end{array}$ \\
\hline & V6 & $\begin{array}{l}\text { Ser bem respeitado - Ter o respeito dos demais indivíduos de forma } \\
\text { positiva, ser visto e reconhecido de forma honrosa. }\end{array}$ \\
\hline
\end{tabular}

Fonte: Elaboração do autor. 
Tabela 2-Cadeias identificadas nas entrevistas - Respectivos elementos formadores e frequência

\begin{tabular}{|c|c|c|}
\hline & CADEIAS & FREQUÊNCIA \\
\hline 1 & $\begin{array}{l}\text { A } 1-\mathrm{C} 1-\mathrm{V} 1 \\
\text { Convivência } \rightarrow \text { Camaradagem } \rightarrow \text { Relações Calorosas } \\
\text { com Terceiros }\end{array}$ & 12 \\
\hline 2 & $\begin{array}{l}\mathrm{A} 1-\mathrm{C} 3-\mathrm{V} 2 \\
\text { Convivência } \rightarrow \text { Identificação } \rightarrow \text { Pertencimento }\end{array}$ & 12 \\
\hline 3 & $\begin{array}{l}\mathrm{A} 1-\mathrm{C} 5-\mathrm{V} 3 \\
\text { Convivência } \rightarrow \text { Proteção } \rightarrow \text { Segurança }\end{array}$ & 12 \\
\hline 4 & $\begin{array}{l}\text { A } 1-\mathrm{C} 2-\mathrm{V} 1 \\
\text { Convivência } \rightarrow \text { Interação Social } \rightarrow \text { Relações Caloro- } \\
\text { sas com Terceiros }\end{array}$ & 11 \\
\hline 5 & $\begin{array}{l}\mathrm{A} 1-\mathrm{C} 6-\mathrm{V} 3 \\
\text { Convivência } \rightarrow \text { Cuidado } \rightarrow \text { Segurança }\end{array}$ & 10 \\
\hline 6 & $\begin{array}{l}\mathrm{A} 1-\mathrm{C} 4-\mathrm{V} 2 \\
\text { Convivência } \rightarrow \text { Afirmação da Identidade } \rightarrow \text { Pertenci- } \\
\text { mento }\end{array}$ & 9 \\
\hline 7 & $\begin{array}{l}\text { A } 1-\mathrm{C} 9-\mathrm{V} 4 \\
\text { Convivência } \rightarrow \text { Afirmação da Masculinidade } \rightarrow \\
\text { Autorrealização }\end{array}$ & 4 \\
\hline 8 & $\begin{array}{l}\mathrm{A} 1-\mathrm{C} 10-\mathrm{V} 4 \\
\text { Convivência } \rightarrow \text { Valorização } \rightarrow \text { Autorrealização }\end{array}$ & 2 \\
\hline 9 & $\begin{array}{l}\mathrm{A} 1-\mathrm{C} 3-\mathrm{V} 4 \\
\text { Convivência } \rightarrow \text { Identificação } \rightarrow \text { Autorrealização }\end{array}$ & 1 \\
\hline 10 & $\begin{array}{l}\mathrm{A} 1-\mathrm{C} 12-\mathrm{V} 4 \\
\text { Convivência } \rightarrow \text { Felicidade } \rightarrow \text { Autorrealização }\end{array}$ & 1 \\
\hline
\end{tabular}

Fonte: Elaboração do autor 
Tabela 3 - Cadeias de percepções dominantes - Respectivos códigos, nomes, elementos formadores e frequências

\begin{tabular}{|c|c|c|}
\hline CÓDIGO & $\begin{array}{l}\text { NOME E ELEMENTOS FORMA- } \\
\text { DORES }\end{array}$ & FREQUÊNCIA \\
\hline \multicolumn{3}{|c|}{ Atributos } \\
\hline A1 & Convivência & 12 \\
\hline \multicolumn{3}{|c|}{ Consequências } \\
\hline C1 & Camaradagem & 12 \\
\hline $\mathrm{C} 2$ & Interação Social & 11 \\
\hline $\mathrm{C} 3$ & Identificação & 12 \\
\hline $\mathrm{C} 4$ & Afirmação da Identidade & 9 \\
\hline $\mathrm{C} 5$ & Proteção & 12 \\
\hline $\mathrm{C} 6$ & Cuidado & 10 \\
\hline \multicolumn{3}{|c|}{ valores } \\
\hline V1 & Relações Calorosas com Terceiros & 12 \\
\hline V2 & Pertencimento & 13 \\
\hline V3 & Segurança & 12 \\
\hline
\end{tabular}

Fonte: Elaboração do autor

Inicialmente, cumpre notar a baixa complexidade do MHV gerado por esta pesquisa frente àquela que não raro se encontra em estudos acadêmicos sobre este assunto, a começar pela identificação de um único atributo. O motivo para esse fenômeno foi - como será visto mais adiante - a homogeneidade verificada no modo de pensar dos entrevistados, característica que foi confirmada pelo resultado da observação não participante. Isso se traduziu em forte concentração das observações em seis cadeias com registro de nove ou mais ocorrências entre os 14 entrevistados (ver Tabela 3).

Passando-se à interpretação do $\mathrm{MHV}$, vê-se que há um único atributo: a convivência. Ao início de todas as 14 entrevistas, a opinião dos Harleyros foi muito específica neste ponto: o que era primariamente importante no pertencimento à Rio H.O.G. era a convivência que isso implicava.

Definida como a experiência de encontrar e de estar com os amigos, de conversar e de estar com o grupo, a importância desse 
fenômeno ficou muito clara durante a observação não participante, conforme se percebeu que o evento café da manhã dos sábados e que os passeios em grupo foram idealizados exatamente com esta finalidade: promover o congraçamento e garantir o reforço dos laços - elementos que se mostraram especialmente valorizados pela maioria dos respondentes. E, com a convivência, o relacionamento até então utilitário com os demais membros se transforma em afetivo, revelando-se como um bônus a esses sujeitos.

Assim, a comunidade da marca Rio H.O.G. cumpre o papel de garantir autenticidade e identidade aos membros (MUÑZ; O'GUINN, 2001), conforme seus membros estendem e forjam suas identidades por meio da convivência com os demais integrantes do grupo (BAUMAN, 2001).

Esse fenômeno encontra respaldo na literatura de marketing dedicada ao estudo dos grupos de referência, já que esses são relevantes para o fortalecimento da identificação com o produto envolvido, ao possibilitarem o convívio de pessoas que buscam o compartilhamento por uma paixão (SOLOMON, 2010). Ali se percebe, ainda, forte compartilhamento de crenças e de atividades comuns, fenômeno evidenciado principalmente por intermédio dos valores comuns, da lealdade e das relações afetivas (BRINT, 2001), assim como, sólida agregação social dos membros conforme eles manifestam as valorizações referentes à marca (SCHOUTEN; McALEXANDER; KOENIG, 2002).

As consequências dominantes na pesquisa foram de seis ordens, todas com números de menções muito próximos, variando entre nove e doze menções cada: identificação, camaradagem, proteção, interação social, cuidado e afirmação da identidade.

Na literatura de marketing concernente à comunidades de marca, essas características têm sido salientadas, com o desejo de pertencimento de um indivíduo estando diretamente relacionado com a sua busca pela identidade social e pela identificação com o grupo a que deseja fazer parte (TAJFEL, 1978; MUÑIZ; O'GUINN, 2001; HEERE et al., 2011).

Partindo-se do princípio de que os consumidores (re)constroem sua identidade com base nas experiências de consumo com as marcas e vice-versa (SOUZA NETO et al., 2004), as marcas auxiliam 
esses consumidores a poder ser quem querem ser ou parecer. Por seu turno, essa (re)construção de identidade ajuda a compreender por que os consumidores iniciam, continuam ou desfazem o relacionamento com uma marca ao longo do tempo, além de ajudar a entender "(...) que ações a marca tem promovido ou deveria promover para construir uma identidade que crie empatia e ou identificação com o consumidor" (MELLO; FONSÊCA, 2007, p. 2).

Não é por outro motivo que essas comunidades podem compor as descrições que o consumidor faz de si próprio quanto às características definidoras dos grupos sociais a que pertencem, constituindo-se na forma como esse sujeito define seus próprios atributos e como avalia suas próprias qualidades - ou seja, seu autoconceito (SIRGY, 1982). E, por conseguinte, o relacionamento marca-consumidor terá sua longevidade ditada por dois elementos: a forma como o consumidor percebe a marca, e a maneira como ele entende que a marca o percebe (BLACKSTON, 1993; FONSÊCA, 2006; PATTERSON; O'MALLEY, 2006).

Três foram os valores pessoais das cadeias de percepção dominantes verificadas na pesquisa: pertencimento, segurança e relações calorosas com terceiros. No caso do valor pessoal pertencimento, construto definido como necessidade de inclusão, de pertencer a um grupo ou a uma comunidade, ele foi 1) identificado em seguida a duas consequências do atributo convivência: identificação e afirmação da identidade, ou seja, do interesse por grupos ou pessoas que possuem considerável afinidade e estilo de vida semelhante; e 2) o principal motivo na mobilização desses homens para estar reunidos todos os sábados, em seus encontros nas instalações da Rio Harley-Davidson, e até mesmo fora dela.

De fato, parece lógico que o pertencimento tenha sido valor muito evidenciado na pesquisa, com o maior número de citações nas entrevistas. Afinal, fazer parte de uma comunidade de marca traz implícita esta inclusão: não somente a comunidade de marca é importante para o indivíduo, como também exerce influência sobre o seu desejo de pertencimento a tal grupo (SCHOUTEN; McALEXANDER, 1995).

Por seu turno, esse efeito tangencia o conceito de engajamento da comunidade de marca (ALGESHEIMER; DHOLKRIA; HERR- 
MANN, 2005), que remete a influências positivas de identificação com a comunidade de marca por meio da motivação intrínseca do consumidor para interagir e ou para cooperar com os membros da comunidade.

Nas entrevistas, transpirava fortemente o desejo de fazer parte do grupo - da "tribo" - de se comportar de maneira semelhante, de interagir com os amigos, porém, preservando e fortalecendo as identidades individuais:

Isso aqui é muito mais do que apenas pessoas que possuem a mesma marca de moto. Estar na H.O.G. é fazer parte de uma tribo, uma família mesmo. (Entrevistado 11)

Aqui você tem todo tipo de gente, com idades diferentes, rendas diferentes, profissões diferentes, histórias diferentes... Não importa se você é branco, negro, jovem, idoso, tatuado ou não... Se você tem uma Harley-Davidson, é nosso irmão. (Entrevistado 8)

O pessoal que convive com a gente fora daqui fala que a gente só conversa sobre HD, come HD, respira HD, dorme HD... Que somos fanáticos, e é verdade. E quando chegamos aqui, não tem como o cara não mergulhar de cabeça nessa atmosfera. (Entrevistado 1)

O segundo valor destacado - as relações calorosas com terceiros, definidas como o desejo de ser querido pelos demais indivíduos - foi antecedido por duas consequências ao atributo convivência: camaradagem e interação social, ou seja, da oportunidade de usufruir de amizade, de companheirismo, de cumplicidade, de conexão, de união, de compartilhamento da vida. Esse valor também parece indicar que fazer parte da Rio H.O.G. implica se beneficiar de algo além daquilo que tradicionalmente se poderia esperar de uma comunidade de marca.

Uma forma de entender esse fenômeno pode ser por meio do interacionismo simbólico, que compreende o "eu" através dos significados edificados nas interações sociais - isto é, entre pelo menos duas pessoas. Associar esse modo de pensar à concepção de construção de Goffman (2007) para esse mesmo “eu” reforça 
esse posicionamento: trata-se também de um acordo social, onde as pessoas atuam, segundo sua metáfora teatral, reciprocamente, na preservação das faces envolvidas em determinada interação (FREITAS; LEÃO, 2011).

As entrevistas, assim como a observação não participante, confirmaram que essas relações calorosas existem representadas por uma forte ligação afetiva entre os membros, a qual, em muitos casos, transcende a mera convivência social, gerando vínculos de amizade intensos:

Gosto muito desse clima familiar que a H.O.G. tem, onde as pessoas fazem parte da vida umas das outras. Amo essa turma... É com essa gente que quero envelhecer! (Entrevistado 7)

É muito bom ter pessoas com quem compartilhar as coisas boas e ruins da vida. Somos uma família mesmo! Família que se ama, se curte... Às vezes sai até uns "arranca rabos", mas depois fazemos as pazes e a vida continua. (Entrevistado 14)

Amizade em minha opinião é um tesouro. Amizade de verdade não se encontra em qualquer lugar. Aqui eu tenho amigos mais chegados que membros da minha própria família. (Entrevistado 2)

O terceiro valor destacado - a segurança, definida como senso de cuidado, de proteção, de abrigo, de amparo - traduz a sensação de estar protegido quando se está com o grupo, e mostra que, quando partícipes da Rio H.O.G., esses indivíduos buscam, fundamentalmente, evitar infortúnios. A Rio H.O.G. é o porto seguro deles, é a sua garantia de que ali se encontram a salvo de qualquer intempérie, justificando por que esse valor surgiu após as consequências proteção e cuidado.

Essa verificação reforça o princípio de que um grupo social pode ser considerado uma comunidade conforme se configure num conjunto de indivíduos que apoiam uns aos outros e cuja relação vai além do objetivo utilitário de uma interação particular (ETZIONI, 1996), engajando-se na comunidade por meio do convívio e ou da cooperação mútua (ALGESHEIMER; DHOLAKIA; HERRMANN, 2005). 
Vale notar que essa sensação psicológica de segurança, entendida como o grau em que o indivíduo percebe que o seu ambiente pode ser um condutor para ele assumir riscos interpessoais, já fora identificada por Vivek (2009) como um dos antecedentes do engajamento do consumidor, definido como a intensidade de participação e de conexão deste com as ofertas de uma organização e ou com suas atividades organizadas. E vários trechos das entrevistas da pesquisa dessa dissertação parecem confirmar essa ligação, ao salientarem a importância que os membros da Rio H.O.G. - o "bando" - atribuem à sensação de segurança trazida pelo seu pertencimento à comunidade:

É muito bom saber que você tem amigos por perto, saber que pode procurar sempre que precisar. Aqui um ajuda o outro, se protege... Não encontrei isso em nenhum outro lugar. Só aqui!! (Entrevistado 5)

Estar com o grupo me traz tranquilidade... Sei que estou protegido. Aqui um cuida do outro, seja numa viagem em grupo ou fora daqui... A gente tá sempre se ligando, se vendo, visitando uns aos outros. Pra mim essa segurança é fundamental. (Entrevistado 12)

Esse clima faz a gente se sentir protegido. Se você for um Harleyro parado no acostamento e um outro te avistar, com certeza vai encostar pra te ajudar... Ninguém nos obriga ou manda fazermos isso. É natural... Alguém do nosso bando precisa de ajuda e paramos pra socorrer... (Entrevistado 3)

\section{Considerações finais}

A presente pesquisa evidenciou que a Rio H.O.G transcende uma mera comunidade de marca aos olhos dos seus membros. Mais do que isso, ela se tornou sua família, seu templo, sua proteção, seu porto seguro, seu ambiente social. Os "irmãos" ali se ajudam, cooperam, ensinam, direcionam, encorajam. Estar naquele ambiente garante vários benefícios, começando no convívio social de forma ampla, passando pelos sentimentos de valorização e de autorrealização, e chegando até a reafirmação da masculinidade. Isso se traduz no entendimento de que estar ali pode ser imprescindível à 
existência do membro: ele não larga essa irmandade por nada neste mundo, porque ela é a sua vida.

Seus rituais são uma forma muito importante de alimentar esse laço tribal e de efetivar sua função social, reforçando o sentido de identidade própria, uma quase religiosidade, um forte sentimento de pertença, uma paixão, um verdadeiro narcisismo de grupo (COVA, 1997; COVA; COVA, 2002). Esse clima de relacionamento e de benefícios percebidos a partir dele reforça o posicionamento de fidelização à marca, a partir do estabelecimento de vínculos sociais estabelecidos entre os clientes, e não entre esses e a empresa prestadora do serviço.

Assim, no caso da Rio H.O.G. os membros são o serviço prestado pela Rio H.O.G., comunidade construída à sombra de uma verdadeira comunhão nesse ambiente de camaradagem, que trouxe o envolvimento social e tantas outras consequências, que, por sua vez, garantem o atingimento de valores muito caros a esses membros. Isso ficou muito evidente quando o único atributo identificado na aplicação das entrevistas de laddering foi a convivência. Essa verdadeira comunhão entre os adeptos ultrapassa as hierarquias sociais que existem fora do contexto dos encontros do café da manhã aos sábados. Antes, ela remete à produção de um espírito de communitas (TURNER, 1995), construto que ajuda a compreender o poder da interação de grupo em torno de um ícone central que serve de base para experiências sagradas (BELK; WALLENDORF; SHERRY, 1989).

Nesse particular, a comunidade de marca cumpre, à perfeição, o seu papel na construção do relacionamento da marca Harley-Davidson com os seus clientes, conforme torna esses vínculos sociais difíceis de serem imitados pela concorrência, encorajando os clientes a se manterem no relacionamento (ZEITHAML; BITNER; GREMLER, 2011). Os entrevistados, assim como os demais indivíduos observados durante o período da pesquisa de inspiração etnográfica, demonstraram que não apenas pertencem À Rio H.O.G., mas que a Rio H.O.G. faz parte deles.

Esses achados se encaixam na discussão emergida na pós-modernidade sobre o destaque que os bens passaram a ter no que diz respeito ao desenvolvimento de significados aos indivíduos. À parte a discussão sobre a sacralização dessas posses e de algumas marcas 
colocadas por autores como Belk, Wallendorf e Sherry (1989), permanece a ideia de que, mais do que os seus atributos funcionais, a imagem dos objetos depende da sua contribuição para a autoimagem do consumidor e para a sua felicidade - no sentido de feeling good proposto por Firat e Shultz (1997).

Por fim, vale lembrar que esses achados tangenciam a discussão sobre os pontos de contato entre a comunidade de marca Rio H.O.G., conforme Muñiz e O'Guinn (2001), e a subcultura de consumo dos motociclistas Harley-Davidson, segundo Schouten e McAlexander (1995). A última, que passa a existir quando alguns indivíduos identificam-se com certos objetos e por meio deles, identifica-se com outras pessoas, seria um conceito analítico consolidado na existência de um estatuto de alguma forma marginal e de uma verdadeira ideologia de consumo. Assim, permite conhecer melhor os consumidores e a forma como organizam suas vidas e suas identidades, com o seu padrão de consumo uniforme sendo governado por um conjunto de valores comuns - ou seja, por um ethos comum.

\section{Contribuição TEÓRICA E SUGESTõeS}

Na literatura acadêmica de Administração estrangeira referida à área de comportamento do consumidor em Marketing, os temas Harley Davidson e H.O.G. têm sido analisados à exaustão (ver, por exemplo, SCHOUTEN; McALEXANDER, 1995; OLIVER, 1999; NIMWEGEN; KLEINER, 2000; BAGOZZI; DHOLAKIA, 2006; SCHOUTEN; McALEXANDER; KOENIG, 2007; SCHEMBRI, 2009; AGNIHOTRI, 2013).

Comparativamente, há parcimônia na dedicação brasileira a pesquisas com este foco: busca realizada ao início do ano de 2016 na base Spell por artigos de Administração em português contendo as palavras Harley e H.O.G. (ou HOG) no título ou nas palavraschave, com data de publicação entre 2000 e 2015, identificou apenas dois: Rimoli, Noronha e Serralvo (2013) e Almeida et al. (2013). Em outras bases foram encontrados ainda o trabalho de Scharf (2011) e de Pinto (2011). Portanto, fica evidenciada a contribuição da presente pesquisa a esse tema.

Além disso, embora não tenha sido o propósito precípuo da presente pesquisa, os resultados ajudam a reforçar o significado 
experiencial da marca Harley-Davidson no contexto da H.O.G. brasileira, tal como Schembri (2009) o fez, no caso da H.O.G. australiana.

Utilizando a quarta dimensão do consumo proposta pelo modelo analítico de Holt (1995) - o consumo enquanto atuação - Schembri (2009) mostrou que a H.O.G. daquele país propicia a socialização, a interação e uma conexão emocional entre os seus membros. Com isso, o consumo australiano das motocicletas Harley-Davidson mostra-se uma ferramenta de socialização, e, ao envolver os consumidores em uma teia de relacionamentos que co-constrem a experiência da marca, reforça a teoria do consumo como atuação. Exatamente como aqui se observou, no caso da Rio H.O.G.

No que tange à maior contribuição teórica trazida pela presente pesquisa, ela se baseia no fato de que:

A surpresa é um critério de validade na pesquisa qualitativa e tem uma importância para essa tradição tanto no que diz respeito à descoberta de evidências inspiradoras a novas formas de pensamento sobre determinado tema, quanto à mudança de mentalidade já cristalizada em torno do fenômeno, padrões esses carentes de serem revistos ou aprofundados sob diferentes prismas para a teoria, para o método ou mesmo para o conhecimento popularmente difundido na sociedade (PAIVA Jr.; LEÃO; MELLO, 2011, p. 202).

Nesse sentido, após tantas manifestações de forte envolvimento emocional existente entre os membros da Rio H.O.G., de prazer nessa convivência e da própria contundência das declarações quanto aos benefícios pessoais que esse pertencimento traz aos membros, surpreendeu e mostrou-se contraintuitivo que a felicidade tenha sido tão pouco mencionada como sentimento que permeia essas relações.

Digressões a respeito desse resultado podem se iniciar com a definição de felicidade (ou bem-estar) como "julgamento feito pelos consumidores quanto à extensão da contribuição significativa trazida à sua qualidade de vida pela companhia ou marca focal" (MERUNKA; SIRGY, 2011, p. 21). Em seguida, pode-se remeter a uma área emergente de estudos de comportamento do consumidor em Marketing: a pesquisa de serviço transformativa (PST), voltada à expansão da visão unilateral de resultados financeiros para a visão 
dos impactos dos serviços na sociedade de uma forma ampla, onde a grande questão tem sido as consequências da prestação dos serviços ao bem-estar (ANDERSON et al., 2013; OSTROM et al., 2010).

Esta seria uma interessante sugestão de futuros estudos: investigar por que, apesar do forte envolvimento emocional existente entre os membros da Rio H.O.G, a felicidade foi tão pouco mencionada como sentimento que permeia essas relações. Também seria instigante investigar os antecedentes a tão elevada homogeneidade, nessa seleção de sujeitos, na forma de qualificar os atributos desse serviço.

Cumpre registrar, ainda, que, além das naturais limitações percebidas no trabalho de campo, outra não prevista inicialmente emergiu nesta fase: a influência que pode ter a mediação dos não humanos na fase da observação não participante configurada na fase de inspiração etnográfica (TURETA; ALCADIPANI, 2011).

De fato, pode-se imaginar que esses elementos materiais (a ambiência da concessionária, as cores e a iluminação dos salões, a exposição das motocicletas no salão principal, o ronco dos motores, a música que rege os encontros) tenham, mesmo que de forma limitada, (re)configurado a relação do observador com o seu objeto de estudo.

\section{REFERÊNCIAS}

AGNIHOTRI, A. Turnaround of Harley Davidson - cult brand or strategic fit approach? Journal of Strategic Marketing, 2013.

ALFINITO, F.; TORRES, C. Modelo de influência cultural no consumo: uma proposta baseada em axiomas sociais. Revista de Administração Mackenzie, v. 13, n. 5, p. 15-38, 2012.

ALGESHEIMER, R.; DHOLAKIA, U. The long-term effects of joining and participating in customer communities. EUROPEAN MARKETING ASSOCIATION, May, 2008, Provo. Anais... Provo: 37th EMAC Conference, Brighton. London, 2008.

ALGESHEIMER, R.; DHOLAKIA, U.; BORLE, S. The impact of customer community participation on customer behaviors: an empirical investigation. Marketing Science, v. 29, n. 4, p. 756-769, 2010.

ALGESHEIMER, R.; DHOLAKIA, U.; HERRMANN, A. The social influence of brand community: evidence from European car clubs. Journal of Marketing, v. 69, n. 3, p. 19-30, 2005.

ALMEIDA, L.; TAVARES, M.; URDAN, A.; TEIXEIRA, D. Comunidade de marcas e os proprietários de Harley-Davidson de Belo Horizonte. Revista Gestão \& Tecnologia, v. 13, n. 3, set./dez. 2013. 
ALMEIDA, S.; MAZZON, J.; MULLER NETO, H.; DHOLAKIA, U. Efeitos da comunidade de origem no participante de comunidades virtuais de marca. RAE - Revista de Administração de Empresas, v. 52, n. 2, 204-216, mar./abr. 2012.

ALVARO, P. Depoimento [MAR., 2014]. Entrevistador: Eduardo Zafaneli. Rio de Janeiro: Unidade Rio Harley-Davidson, 2014.

AÑAÑA, E.; NIQUE, W. O Valor dos Valores: uma abordagem exploratória do cerne da cultura e da sua influência na avaliação de uma marca. XXXII Encontro da ANPAD (EnANPAD). Anais... Rio de Janeiro-RJ, set. 2008.

ANDERSON, L.; OSTROM, A. L.; CORUS, C.; FISK, R. P.; GALLAN, A.S.; GIRALDO, M.; MENDE, M.; MULDER, M.; RAYBURN, S. W.; ROSENBAUM, M. S.; SHIRAHADA, K.; WILLIAMS, J. D. Transformative service research: an agenda for the future. Journal of Business Research, vol. 66, n. 8, p. 1.203-1.210, 2013.

ARGO, J. J.; DAHL, D. W.; MANCHANDA, R. V. The Influence of a Mere Social Presence in a Retail Context. Journal of Consumer Research, v. 32, p. 207-212, 2005.

ARNOULD, E.; THOMPSON, C. Consumer Culture Theory (CCT): Twenty Years of Research. The Journal of Consumer Research, v. 31, n. 4, p. 868-882, 2005.

BAGOZZI, R.; DHOLAKIA, U. M. Antecedents and purchase consequences of customer participation in small group brand communities. International Journal of Research in Marketing, v. 23, p. 45-61, 2006.

BAUDRILLARD, J. A sociedade de consumo. Lisboa: Edições 70, 1995.

BAUMAN, Z. Modernidade líquida. Rio de Janeiro: Zahar, 2001.

BEARDEN, W.; ETZEL, M. Reference group influence on product and brand purchase decisions. Journal of Consumer Research, v. 9, p. 183-194, 1982.

BELK, R.; WALLENDORF, M.; SHERRY, J. The Sacred and the Profane in Consumer Behaviour: Theodicy on the Odissey. Journal of Consumer Research, v. 16, n. 1, p. 1-38, 1989.

BLACKWELL, R.; MINIARD, P.; ENGEL, J. Comportamento do Consumidor. São Paulo: Thompson, 2011.

BROCATO, E. D.; VOORHEES, C. M.; BAKER, J. Understanding the Influence of Cues from Other Customers in the Service Experience: A Scale Development and Validation. Journal of Retailing, v. 88, n. 3, p. 384-398, 2012.

CAMPBELL, C.; BARBOSA, L. Cultura, Consumo e Identidade. Rio de Janeiro: Ed. FGV, 2006.

CARDOSO SOBRINHO, C.; VILAS BOAS, L.; MARTINS, A.; COELHO, G. Uma comparação entre as técnicas hard e soft laddering aplicadas à percepção de valor de acadêmicos de administração em relação a uma instituição de ensino superior na cidade de Rio Verde-GO. RAI Revista de Administração e Inovação, v. 7, n. 4, out./dez. 2010.

CARLSON, B.; SUTER, T.; BROWN, T. Social versus psychological brand community: The role of psychological sense of brand community. Journal of Business Research, v. 61, p. 284-291, 2008. 
COVA, B. Community and Consumption: Towards a definition of the "linking value" of product or services. European Journal of Marketing, v. 31, n. 3, 1997.

COVA, B.; COVA, V. Tribal Marketing: The tribalisation of society and its impact on the conduct of marketing. European Journal of Marketing, 36, n. 5, p. 595-620, 2002.

DHOLAKIA, U.; BLAZEVIC, V.; WIERTZ, C. Communal service delivery: how customers benefit from participation in firm-hosted virtual P3 communities. Journal of Service Research, v. 12, n. 2, p. 208-226, 2009.

DIBLEY, A.; BAKER, S. Uncovering the links between brand choice and personal values among young british and spanish girls. Journal of Consumer Behaviour, v. 1, n. 1, p. 77-793, 2001.

DOUGLAS, M.; ISHERWOOD, B. O Mundo dos Bens. Rio de Janeiro: Ed. UFRJ, 2006.

ESCUDERO, F.; PRADO, P. Análise das metas do consumidor, uma contribuição, metodológica. RAE - Revista de Administração de Empresas, v. 7, n. 2, Art. 22, 2008.

ETZIONI, A. The new golden rule: community and morality in a democratic society. New York: Basic Books, 1996.

FEATHER, N. Values in Education and Society. New York: Free Press, 1975.

FIRAT, A.; SCHULTZ, C. From segmentation to fragmentation markets and marketing strategy in the postmodern era. European Journal of Marketing, v. 31, n. 3/4, 1997.

FLICK, U. Qualidade na Pesquisa Qualitativa. Porto Alegre: Artmed, 2009

FLINT, D.; WOODRUFF, R.; GARDIAL, S. Customer Value Change in Industrial Marketing Relationships - A Call for New Strategies and Research. Industrial Management, v. 26, p. 163-175, 1997.

FREITAS, G.; LEÃO, A. O que "eu" sou nós "combinamos" no nosso "encontro": uma busca pela compreensão do "eu" em comunidades virtuais de marca. Revista Alcance Eletrônica, v. 18, n. 2, abr./jun. p. 155-166, 2011.

FÜLLER, J.; MATZLER, K.; HOPPE, M. Brand community members as a source of innovation. Journal of Product Innovation Management, v. 25, n. 6, p. 608-619, 2008.

GIL, A. Métodos e Técnicas de Pesquisa Social. São Paulo: Atlas, 2011.

GIRALDI, J.; IKEDA, A. Valores pessoais como base para segmentação estratégica: um estudo com profissionais paulistas. Revista Brasileira de Gestão de Negócios, v. 12, n. 32, p. 322-340, 2010.

GOFFMAN, E. A representação do eu na vida cotidiana, 14. ed. Petrópolis: Vozes, 2007.

GONÇALVES, R. Identidade, consumo e sociabilidade. Revista Estudos e Pesquisas em Psicologia, n. 1, p. 185-198, 2009.

HABIBI, M.; LAROCHE, M.; RICHARD, M. The roles of brand community and community engagement in building brand trust on social media. Computers in Human Behavior, v. 37, p. 152-161, 2014.

HACKEL, L.; LOOSER, C.; VAN BAVEL, J. Group membership alters the threshold for mind perception: The role of social identity, collective identification, and intergroup threat. Journal of Experimental Social Psychology, v. 52, p. 15-23, 2014. 
HALL, S. A identidade cultural na pós-modernidade. Rio de Janeiro: DP\&A, 2006.

HAWKINS, D.; MOTHERSBAUGH, D.; BEST, R. Comportamento do Consumidor: Construindo a Estratégia de Marketing, 10. ed. Rio de Janeiro: Campus, 2007.

HEERE, B.; WALKER, M.; YOSHIDA, M.; KO, Y.; JORDAN, J.; JAMES, J. Brand Community Development Through Associated Communities: Grounding Community Measurement Within Social Identity Theory. Journal of Marketing Theory and Practice, v. 19, n. 4, p. 407-422, 2011.

HENRIQUE, J.; MONTEIRO, P.; MATOS, C. As influências dos valores pessoais nas atitudes e nas fases da lealdade. Revista de Ciências da Administração, v. 15, n. 36, p. 101-115, mai./ ago. 2013.

HICKMAN, T.; WARD, J. The Dark Side of Brand Community: Inter-Group Stereotyping, Trash Talk, and Schadenfreude. Advances in Consumer Research, v. 34, p. 314-319, 2007.

HOFSTEDE, G. Culture's Consequences. Thousand Oaks: Sage Publications, 2001.

HOLT, D. Poststructuralist lifestyle analysis: conceptualizing the social patterning of consumption in postmodernity. Journal of Consumer Research, v. 23, n. 4, p. 326-350, 1997.

HYMAN, H. The psychology of status. Archives of Psychology, v. 269, p. 5-91. Reprint in H. Hyman \& E. Singer (Orgs.). Readings in reference group theory and research (p. 147-165). New York: Free Press, London: Collier-Macmillan Limited, 1942.

IKEDA, A.; CAMPOMAR, M.; CHAMIE, B. Laddering: revelando a coleta e interpretação dos dados. Brazilian Journal of Marketing - BJM. Revista Brasileira de Marketing - ReMark Edição Especial, v. 13, n. 4, p. 49-66, set. 2014.

KAHLE, L. Social values and social change: Adaptation to life in America. New York: Praeger, 1983.

KELMAN, H. Processes of opinion change. Public Opinion, v. 25, n. 1, p. 57-78, 1961.

LARAIA, R. B. Cultura: um conceito Antropológico. Rio de Janeiro: Ed. Jorge Zahar, 2006.

MAFFESOLI, M. The time of the tribes: The decline of individualism in mass society. Thousand Oaks, CA: Sage, 1996.

MASLOW, A. H. Motivation and personality. New York: Harper \& Row, 1954.

McCRACKEN, G. Cultura e Consumo: novas abordagens ao caráter simbólico dos bens e das atividades de consumo. Rio de Janeiro: MAUAD, 2003.

MELLO, S. C. B.; FONSÊCA, F. R. B. (Re)compreendendo o relacionamento marca-consumidor. Revista Faces, v. 6, n. 1, 2007.

MERUNKA, D.; SIRGY, M. Distinguishing consumer satisfaction from consumer well-being in brand post-purchase behavior: a positive psychology perspective. Proceedings for the Inaugural Conference on Positive Marketing, Center for Positive Marketing. New York, NY, p. 21-22, 2011.

MOURALI, M.; LAROCHE, M.; PONS, F. Individualistic Orientation and Consumer Susceptibility to Interpersonal Influence. Journal of Services Marketing, v. 19, n. 3, p. 164-173, 2005. 
MUÑIZ, A. M. Jr; O'GUINN, T. C. Brand community and the sociology of brands. Journal of Consumer Research, v. 27, n. 4, p. 412-432, 2001.

MUÑIZ, A. M. Jr; SCHAU, H. J. Religiosity in the abandoned apple Newton brand community. Journal of Consumer Research, v. 31, n. 4, p. 737-747, 2005.

NIMWEGEN, J.; KLEINER, B. Harley-Davidson Motor Company. Journal Management Research News, v. 23, n. 7/8, 2000.

OLIVER, R. Whence consumer loyalty? Journal of Marketing, v. 63, p. 33-44, 1999.

OSTROM, A. L.; BITNER, M. J.; BROWN, S. W.; BURKHARD, K. A.; GOUL, M.; SMITH-DANIELS, V.; DEMIRKAN, H.; RABINOVICH, E. Moving forward and making a difference: research priorities for the science of service. Journal of Service Research, v. 13, n. 1, p. 4-36, 2010.

PAIVA Jr., F.; LEÃO, A.; MELLO, S. Validade e Confiabilidade na Pesquisa Qualitativa em Administração. Revista de Ciências da Administração, v. 13, n. 31, p. 190-209, 2011.

PIMENTA, M.; PIATO, E.; VILAS BOAS, L. Esportivo ou retrô? Análise comparativa dos valores pessoais de compradores de automóveis. Revista de Ciências da Administração, v. 16, n. 40, p. 123-138, set./dez. 2014.

PINTO, F. Você tem uma moto ou uma Harley? Vínculos com a marca Harley-Davidson em São Paulo, 2011. Tese (Doutorado em Antropologia Social) - Curso de Pós-graduação em Antropologia Social, Faculdade de Filosofia, Letras e Ciências Humanas, Universidade de São Paulo, São Paulo, 2011.

RECUERO, R. Considerações sobre a Difusão de Informações em Redes Sociais na Internet. INTERCOM - VIII Congresso Brasileiro de Ciências da Comunicação da Região Sul. Anais... Passo Fundo-RS, jun. 2007.

REYNOLDS, T. J.; GUTMAN, J. Laddering theory, method, analysis and interpretation. Journal of Advertising Research, v. 28, n. 1, p. 11-31, 1988.

REYNOLDS, T.; OLSON, J. Understanding consumer decision making. The means-end approach to marketing and advertising strategy. Mahwah (NJ): Lawrence Erlbaum Associates, Inc., Publishers, 2010.

RIMOLI, C.; NORONHA, L.; SERRALVO, F. Aspectos de inovação e de redes que afetam a imagem da marca: o caso Harley-Davidson e Buell. REAd. Revista Eletrônica de Administração, v. 19, n. 2, p. 401-432, mai./ago. 2013.

ROCHA, E.; BARROS, C. Dimensões culturais do marketing: teoria antropológica, etnografia e comportamento do consumidor. RAE - Revista de Administração de Empresas, v. 46, n. 4, p. 1-12, 2006.

ROCHA, E.; PEREIRA, C. Juventude e consumo: um estudo sobre a comunicação na cultura contemporânea. Rio de Janeiro: Mauad, 2009.

ROKEACH, M. Beliefs, attitudes and values: a theory of organization and change. San Francisco: Jossey-Bass, 1968. 
ROKEACH, M. The nature of human values. New York: Free Press, 1973.

RUST, R., ZEITHAML, V.; LEMON, K. O Valor do Cliente: o modelo que está reformulando a estratégia corporativa. Tradução Nivaldo Montingelli Jr. Porto Alegre: Bookman, 2001.

SASTRE, P.; SERRALVO, F.; MORAS, A. A Influência dos Grupos de Referência no Processo Decisório do Consumidor: um estudo no segmento de veículos utilitários esportivos. IV Encontro de Marketing da ANPAD (EMA). Anais... Florianópolis (SC), ago. 2010.

SCHARF, E. O estilo de vida e a experiência: aspectos da marca no entendimento dos seus usuários. Revista Brasileira de Gestão de Negócios, v. 13, n. 38, p. 99-113, 2011.

SCHAU, H.; MUÑIZ, A.; ARNOULD, E. How brand community practices create value. Journal of Marketing, v. 73, n. 5, p. 30-51, 2009.

SCHEMBRI, S. Reframing brand experience: The experiential meaning of Harley-Davidson. Journal of Business Research, v. 62, p. 1.299-1.310, 2009.

SCHOUTEN, J.; McALEXANDER, J. Subcultures of Consumption: An Ethnography of the New Bikers. The Journal of Consumer Research, v. 22, n. 1, p. 43-61, 1995.

SCHOUTEN, J.; McALEXANDER, J.; KOENIG, H. Transcendent customer experience and brand community. Journal of the Academy of Marketing Science, v. 35, n. 3, p. 357-368, 2007.

SHIBUTANI, T. Reference groups as perspectives. American Journal of Sociology, v. 60, p. 562-569, 1955.

SCHWARTZ, S. H. Universals in the content and structure of values: theoretical advances and empirical tests in 20 countries. Advances in Experimental Social Psychology, v. 25, n. 1, p. 1-65, 1992.

SCHWARTZ, S. H. Are there universal aspects in the content and structure of values? Journal of Social Issues, v. 50, n. 4, p. 19-45, 1994.

SCHWARTZ, S. H. Mapping and interpreting cultural differences around the world. In VINKEN, H.; SOETERS, J. e ESTER P. ed., Comparing cultures, Dimensions of culture in a comparative perspective. Leiden, The Netherlands: Brill, 2004.

SCHWARTZ, S. H. Valores humanos básicos: seu contexto e estrutura intercultural. Tradução Viviane Rios. In: TAMAYO, A.; PORTO, J. (Org.). Valores e comportamento nas organizações. Petrópolis: Vozes, 2005, p. 21-55.

SCHWARTZ, S. H. An Overview of the Schwartz Theory of Basic Values. Online Readings in Psychology and Culture, 2012.

SCHWARTZ, S. H.; CIECIUCH, J.; VECCHIONE, M.; DAVIDOV, F.; FISCHER, R.; BEIERLEIN, C.; KONTY, M. Refining the theory of basic individual values. Journal of Personality and Social Psychology, v. 103, n. 4, p. 663-688, 2012.

SCHWARTZ, S. H.; HUISMANS, S. Value priorities and religiosity in four Western religions. Social Psychology Quarterly, v. 58, n. 2, p. 88-107, 1995.

SOLOMON, M. O Comportamento do Consumidor: Comprando, Possuindo e Sendo. Porto Alegre: Bookman, 9. ed., 2010. 
SOUZA NETO, A. F.; MELlO, S. C. B.; CORDEIRO, A. T.; FONSÊCA, F. R. B. Voltando o carro para trás dos bois: busca da compreensão de nuances do "relacionamento" no contexto de consumo como forma de subsidiar a prática consciente do "marketing de relacionamento" por empresas de serviço. In: ENCONTRO DE MARKETING, 1, 2004, Porto Alegre, RS. Anais... Rio de Janeiro: Anpad, 2004.

TAJFEL, H. The Achievement of Group Differentiation. In: H. Tajfel (Org.). Differentiation Between Social Groups: Studies in the Social Psychology of Intergroup Relations. London: Academic Press, 1978.

TURETA, C.; ALCADIPANI, R. Entre o Observador e o Integrante da Escola de Samba: os Não-Humanos e as Transformações Durante uma Pesquisa de Campo. RAC - Revista de Administração Contemporânea, v. 15, n. 2, art. 3, p. 209-227, mar./abr. 2011.

TURNER, V. The Ritual Process: Structure and Anti-Structure. New York: Aldine de Gruyter, 1995.

VALETTE-FLORENCE, P. Analyse structurelle comparative des composantes des systèms de valeurs selon Kahle et Rokeach. Recherche et Applications en Marketing, v. 3, n. 1, p. 15-34, 1998.

VERGARA, S. Métodos de Pesquisa em Administração. São Paulo: Atlas, 2010.

VILAS BOAS, L.; BUENO, J.; OLIVEIRA, L.; SIQUEIRA, W. Comportamento do consumidor sob a ótica da teoria meios-fim: um estudo sobre os valores pessoais dos discentes do curso de especialização em gestão pública. V Encontro de Marketing da ANPAD (EMA). Anais... Curitiba (PR), ago. 2012.

VIVEK, S. A scale of consumer engagement. Doctoral dissertation (Department of Management and Marketing), University of Alabama, 2009.

ZEITHAML, V.; BITNER, M. J.; GREMLER, D. Marketing de serviços: a empresa com foco no cliente. Porto Alegre: Ed. Bookman, 5. ed., 2011.

Recebido em: 13-04-2017

Aprovado em: 15-09-2017

Avaliado pelo sistema double blind review.

Editor: Coordenação do PPGA/UMESP

Disponível em http://mjs.metodista.br/index.php/roc 